\title{
A Modified ABC Algorithm for Solving Non-Convex Dynamic Economic Dispatch Problems
}

\author{
Hardiansyah \\ Department of Electrical Engineering, Tanjungpura University, Pontianak, West Kalimantan, Indonesia
}

\begin{tabular}{l} 
Article Info \\
\hline Article history: \\
Received Aug 12, 2016 \\
Revised Nov 3, 2016 \\
Accepted Nov 17, 2016 \\
\hline Keyword: \\
Dynamic economic dispatch \\
Modified artificial bee colony \\
algorithm \\
Ramp rate limits \\
Valve-point effects
\end{tabular}

\begin{abstract}
In this paper, a modified artificial bee colony (MABC) algorithm is presented to solve non-convex dynamic economic dispatch (DED) problems considering valve-point effects, the ramp rate limits and transmission losses. Artificial bee colony algorithm is a recent population-based optimization method which has been successfully used in many complex problems. A new mutation strategy inspired from the differential evolution (DE) is introduced in order to improve the exploitation process. The feasibility of the proposed method is validated on 5 and 10 units test system for a $24 \mathrm{~h}$ time interval. The results are compared with the results reported in the literature. It is shown that the optimum results can be obtained more economically and quickly using the proposed method in comparison with the earlier methods.
\end{abstract}

Copyright $@ 2016$ Institute of Advanced Engineering and Science. All rights reserved.

\section{Corresponding Author:}

Hardiansyah,

Department of Electrical Engineering,

Tanjungpura University,

Jalan Ahmad Yani, Pontianak-78124, West Kalimantan, Indonesia.

Email: hardi_eka@yahoo.com

\section{INTRODUCTION}

A power utility needs to ensure that the electrical power is generated with minimum cost. Hence, for economic operation of the system, the total demand must be appropriately shared among the generating units with an objective to minimize the total generation cost of the system. Dynamic economic dispatch (DED) is one of important problems in power system operation and control, which is used to determine the optimal schedule of generating outputs online so as to meet the load demand at the minimum operating cost under various system and operating constraints over the entire dispatch periods. DED is an extension of the conventional economic dispatch (ED) problem that takes into consideration the limits on the ramp rate of generating units to maintain the life of generation equipment [1-2].

Since the DED problem was introduced, several optimization techniques and procedures have been used for solving the DED problem with complex objective functions or constraints. There were a number of classical methods that have been applied to solve this problem such as gradient projection method, Lagrange relaxation, and linear programming [3-5]. Most of these methods are not applicable for non-smooth or nonconvex cost functions. To overcome this problem, many stochastic optimization methods have been employed to solve the DED problem, such as genetic algorithm (GA) [6], simulated annealing (SA) [7], differential evolution (DE) [8], particle swarm optimization (PSO) [9], hybrid EP and SQP [10], deterministically guided PSO [11], artificial bee colony (ABC) algorithm [12], and imperialist competitive algorithm (ICA) [13]. Many of these techniques have proven their effectiveness in solving the DED problem without any or fewer restrictions on the shape of the cost function curves.

Swarm intelligence has become a research interest to different domain of researchers in recent years. These algorithms simulate the food foraging behavior of a flock of birds or swarm of bees. Motivated by the foraging behavior of honey bees, researchers have initially proposed artificial bee colony (ABC) algorithm 
for solving various optimization problems [14-15]. Artificial bee colony (ABC) algorithm is a relatively new member of swarm intelligence. ABC tries to model natural behavior of real honey bees in food foraging. Honey bees use several mechanisms like waggle dance to optimally locate food sources and to search new ones. This makes them a good candidate for developing new intelligent search algorithms. Despite the simplicity and the superiority of $\mathrm{ABC}$ algorithm, recent studies reported that it suffers from a poor exploitation process and a slow convergence rate. To overcome these pitfalls, some research papers have introduced modifications to the classical $\mathrm{ABC}$ algorithm in order to improve its performance and tackle more complex real-world problems [16-17].

This paper presents a novel optimization method based on modified artificial bee colony (MABC) algorithm applied to dynamic economic dispatch in a practical power system while considering some nonlinear characteristics of a generator such as valve-point effect, the ramp rate limits, and transmission losses. The proposed method is tested for two different systems and the results are compared with other methods reported in recent literature in order to demonstrate its performance.

\section{RESEARCH METHOD}

\subsection{DED Problem Formulation}

The objective of DED problem is to find the optimal schedule of output powers of online generating units with predicted power demands over a certain period of time to meet the power demand at minimum operating cost.

The fuel cost function of the generating unit is expressed as a quadratic function of real power generation. The objective function of the DED problem is

$$
\begin{gathered}
\min F_{T}=\sum_{t=1}^{T} \sum_{i=1}^{N} F_{i, t}\left(P_{i, t}\right)=\sum_{t=1}^{T} \sum_{i=1}^{N}\left(a_{i} P_{i, t}^{2}+b_{i} P_{i, t}+c_{i}\right) \\
\quad \text { for } i=1,2, \cdots, N ; t=1,2, \ldots, T
\end{gathered}
$$

where $F_{i, t}$ is the fuel cost of unit $i$ at time interval $t$ in $\$ / \mathrm{hr}, a_{i}, b_{i}$, and $c_{i}$ are the cost coefficients of generating unit $i, P_{i, t}$ is the real power output of generating unit $i$ at time period $t$ in $\mathrm{MW}$, and $N$ is the number of generators. $T$ is the total number of hours in the operating horizon.

The valve-point effects are taken into consideration in the DED problem by superimposing the basic quadratic fuel-cost characteristics with the rectified sinusoid component as follows [18]:

$$
\min F_{T}=\sum_{t=1}^{T} \sum_{i=1}^{N} F_{i, t}\left(P_{i, t}\right)=\sum_{t=1}^{T} \sum_{i=1}^{N}\left(a_{i} P_{i, t}^{2}+b_{i} P_{i, t}+c_{i}+\left|e_{i} \times \sin \left(f_{i} \times\left(P_{i, \min }-P_{i, t}\right)\right)\right|\right)
$$

where $F_{T}$ is total fuel cost of generation in $(\$ / \mathrm{hr})$ including valve point loading, $e_{i}, f_{i}$ are fuel cost coefficients of unit $i$ reflecting valve-point effects.

The fuel cost is minimized subjected to the following constraints:

1) Active power balance equation

For power balance, an equality constraint should be satisfied. The total generated power should be the same as total load demand plus the total line loss.

$$
\sum_{i=1}^{N} P_{i, t}=P_{D, t}+P_{L, t}
$$

where $P_{D, t}$ and $P_{L, t}$ are the load demand and transmission loss in MW at time interval $t$, respectively. The transmission loss $P_{L, t}$ can be expressed by using $\boldsymbol{B}$ matrix technique and is defined by (4) as,

$$
P_{L, t}=\sum_{i=1}^{n} \sum_{j=1}^{n} P_{i, t} B_{i j} P_{j, t}+\sum_{i=1}^{n} B_{0 i} P_{i, t}+B_{00}
$$

where $B_{i j}, B_{0 i}$, and $B_{00}$ are coefficient of transmission loss. 
2) Minimum and maximum power limits

Generation output of each generator should lie between minimum and maximum limits. The corresponding inequality constraint for each generator is

$$
P_{i, \min } \leq P_{i, t} \leq P_{i, \max }
$$

where $P_{i, \min }$ and $P_{i, \max }$ are the minimum and maximum real power output of unit $i$ in $\mathrm{MW}$, respectively. 3) Ramp rate limits

The actual operating ranges of all online units are restricted by their corresponding ramp rate limits. The ramp-up and ramp-down constraints can be written as (6) and (7), respectively.

$$
\begin{aligned}
& P_{i, t}-P_{i, t-1} \leq U R_{i} \\
& P_{i, t-1}-P_{i, t} \leq D R_{i}
\end{aligned}
$$

where $P_{i, t}$ and $P_{i, t-1}$ are the present and previous power outputs, respectively. $U R_{i}$ and $D R_{i}$ are the ramp-up and ramp-down limits of unit $i$ (in units of MW/time period).

To consider the ramp rate limits and power output limits constraints at the same time, therefore, eqs. (5), (6) and (7) can be rewritten as follows:

$$
\max \left\{P_{i, \min }, P_{i, t-1}-D R_{i}\right\} \leq P_{i, t} \leq \min \left\{P_{i, \max }, P_{i, t-1}+U R_{i}\right\}
$$

\subsection{Artificial Bee Colony (ABC) Algorithm}

Artificial bee colony is one of the most recently defined algorithms by Karaboga in 2005, motivated by the intelligent behavior of honey bees [14-15]. In the ABC system, artificial bees fly around in the search space, and some (employed and onlooker bees) choose food sources depending on the experience of themselves and their nest mates, and adjust their positions. Some (scouts) fly and choose the food sources randomly without using experience. If the nectar amount of a new source is higher than that of the previous one in their memory, they memorize the new position and forget the previous one. Thus, the ABC system combines local search methods, carried out by employed and onlooker bees, with global search methods, managed by onlookers and scouts, attempting to balance exploration and exploitation process.

In the $\mathrm{ABC}$ algorithm, the colony of artificial bees consists of three groups of bees: employed bees, onlooker bees, and scout bees. The main steps of the ABC algorithm are described as follows:

a. Initialize.

b. REPEAT.

c. Place the employed bees on the food sources in the memory;

d. Place the onlooker bees on the food sources in the memory;

e. Send the scouts to the search area for discovering new food sources;

f. Memorize the best food source found so far.

g. UNTIL (requirements are met).

In the $\mathrm{ABC}$ algorithm, each cycle of the search consists of three steps: moving the employed and onlooker bees onto the food sources, calculating their nectar amounts respectively, and then determining the scout bees and moving them randomly onto the possible food source. Here, a food source stands for a potential solution of the problem to be optimized. The ABC algorithm is an iterative algorithm, starting by associating all employed bees with randomly generated food solutions. The initial population of solutions is filled with $S N$ number of randomly generated $D$ dimensions. Let $X_{i}=\left\{x_{i 1}, x_{i 2}, \ldots, x_{i D}\right\}$ represent the $i$ th food source in the population, $S N$ is the number of food source equal to the number of the employed bees and onlooker bees. $D$ is the number of optimization parameters. Each employed bee $x_{i j}$ generates a new food source $v_{i j}$ in the neighborhood of its currently associated food source by (9), and computes the nectar amount of this new food source as follows:

$$
v_{i j}=x_{i j}+\varphi_{i j}\left(x_{i j}-x_{k j}\right)
$$

where $\varphi_{i j}=($ rand-0.5) $\times 2$ is a uniformly distributed real random number within the range [-1, 1], $i \in\{1,2, \ldots, S N\}, k=\operatorname{int}(\operatorname{rand} * S N)+1$ and $k \neq i$, and $j \in\{1,2, \ldots, D\}$ are randomly chosen indexes. The new solution $v_{i}$ will be accepted as a new basic solution, if the objective fitness of $v_{i}$ is smaller than the fitness of $x_{i}$, otherwise $x_{i}$ would be obtained.

A Modified ABC Algorithm for Solving Non-Convex Dynamic Economic Dispatch Problems (Hardiansyah) 
when all employed bees finish this process, an onlooker bee can obtain the information of the food sources from all employed bees and choose a food source according to the probability value associated with the food source, using the following expression:

$$
p_{i}=\alpha \times \frac{f i t_{i}}{\max \left(f i t_{i}\right)}+\beta ; \quad \alpha+\beta=1
$$

where fit $_{i}$ is the fitness value of the solution $i$ evaluated by its employed bee. Obviously, when the maximum value of the food source decreases, the probability with the preferred source of an onlooker bee decreases proportionally. Then the onlooker bee produces a new source according to (9). The new source will be evaluated and compared with the primary food solution, and it will be accepted if it has a better nectar amount than the primary food solution.

After all onlookers have finished this process, sources are checked to determine whether they are to be abandoned. If the food source does not improve after a determined number of the trails "limit", the food source is abandoned. Its employed bee will become a scout and then will search for a food source randomly as follows:

$$
x_{i j}=x_{j \min }+\operatorname{rand}(0,1) *\left(x_{j \max }-x_{j \min }\right)
$$

where $x_{j \min }$ and $x_{j \max }$ are lower and upper bounds for the dimension $j$ respectively.

After the new source is produced, another iteration of the ABC algorithm will begin. The whole process repeats again till the termination condition is met.

\subsection{Modified Artificial Bee Colony (MABC) Algorithm}

Following this spirit, a modified ABC algorithm inspired from differential evolution (DE) to optimize the objective function of the ED problems. Differential evolution is an evolutionary algorithm first introduced by Storn and Price [19-20]. Similar to other evolutionary algorithms, particularly genetic algorithm, DE uses some evolutionary operators like selection recombination and mutation operators. Different from genetic algorithm, DE uses distance and direction information from the current population to guide the search process. The crucial idea behind $\mathrm{DE}$ is a scheme for producing trial vectors according to the manipulation of target vector and difference vector. If the trail vector yields a lower fitness than a predetermined population member, the newly trail vector will be accepted and be compared in the following generation. Currently, there are several variants of DE. The particular variant used throughout this investigation is the $\mathrm{DE} / \mathrm{rand} / 1$ scheme. The differential mutation strategy is described by the following equation:

$$
v_{i}=x_{a}+F\left(x_{b}-x_{c}\right)
$$

where $a, b, c \in S N$ are randomly chosen and mutually different and also different from the current index $i$. $F \in(0,1)$ is constant called scaling factor which controls amplification of the differential variation of $x_{b j}-x_{c j}$.

Based on $\mathrm{DE}$ and the property of $\mathrm{ABC}$ algorithm, we modify the search solution described by (13) as follows:

$$
v_{i j}=x_{a j}+\varphi_{i j}\left(x_{i j}-x_{b j}\right)
$$

The new search method can generate the new candidate solutions only around the random solutions of the previous iteration.

Akay and Karaboga [16] proposed a modified artificial bee colony algorithm by controlling the frequency of perturbation. Inspired by this algorithm, we also use a control parameter, i.e., modification rate $(M R)$. In order to produce a candidate food position $v_{i j}$ from the current memorized $x_{i j}$, improved ABC algorithm uses the following expression [17]:

$$
v_{i j}= \begin{cases}x_{a j}+\varphi_{i j}\left(x_{i j}-x_{b j}\right) & \text { if } R_{i j} \leq M R \\ x_{i j} & \text { otherwise }\end{cases}
$$


where $R_{i j}$ is a uniformly distributed real random number within the range $[0,1]$. The pseudo-code of the modified ABC algorithm is given below:

Initialize the population of solutions $x_{i j}, i=1 . . S N ; j=1 . . D$, trial $_{i}=0 ;$ trial $_{i}$ is the non-improvement number of thesolution $x_{i}$, used for abandonment

Evaluate the population

cycle $=1$

repeat

$\{---$ Produce a new food source population for employed bee --- $\}$

for $i=1$ to $S N$ do

Produce a new food source $v_{i}$ for the employed bee of the food source $x_{i}$ by using (14) and evaluate its quality:

Select randomly $a \neq b \neq i$

$$
v_{i j}= \begin{cases}x_{a j}+\varphi_{i j}\left(x_{i j}-x_{b j}\right), & \text { if } R_{i j} \leq M R \\ x_{i j} & \text { otherwise }\end{cases}
$$

Apply a greedy selection process between $v_{i}$ and $x_{i}$ and select the better one. If solution $x_{i}$ does not improve trial $_{i}=$ trial $_{i}+1$, otherwise trial $_{i}=0$

end for

Calculate the probability values $p_{i}$ by $(10)$ for the solutions using fitness values:

$$
p_{i}=\alpha \times \frac{f i t_{i}}{\max \left(f i t_{i}\right)}+\beta ; \quad \alpha+\beta=1
$$

\{--- Produce a new food source population for onlooker bee --- $\}$

$t=0, i=1$

repeat

if random $<p_{i}$ then

Produce a new $v_{i j}$ food source by (14) for the onlookerbee:

Select randomly $a \neq b \neq i$

$$
v_{i j}= \begin{cases}x_{a j}+\varphi_{i j}\left(x_{i j}-x_{b j}\right), & \text { if } R_{i j} \leq M R \\ x_{i j} & \text { otherwise }\end{cases}
$$

Apply a greedy selection process between $v_{i}$ and $x_{i}$ and select the better one. If solution $x_{i}$ does not improve trial $_{i}=$ trial $_{i}+1$, otherwise trial $_{i}=0$

$t=t+1$

end if

until $(t=S N)$

$\{---$ Determine scout bee --- $\}$

if $\max \left(\right.$ trial $\left._{i}\right)>$ limit then

Replace $x_{i}$ with a new randomly produced solution by (11)

$$
x_{i j}=x_{j \min }+\operatorname{rand}(0,1) *\left(x_{j \max }-x_{j \min }\right)
$$

end if

Memorize the best solution achieved so far

cycle $=$ cycle +1

until (cycle = Maximum Cycle Number)

\section{RESULTS AND ANALYSIS}

The DED problem was solved using the MABC algorithm and its performance is compared with other methods reported in recent literature. The proposed technique has been applied to 5 and 10 unit test systems. The algorithm was implemented in MATLAB 7.1 on a Pentium IV personal Computer with 3.6 
$\mathrm{GHz}$ speed processor and 2 GB RAM. For all cases, the dispatch horizon is selected as one day with 24 dispatch periods of each one hour.

Case 1: 5-unit system

The first test system is a 5-unit test system. The technical data of the units are taken from [21]. In this test system, valve-point effect, the ramp rate limits, and transmission losses are considered. The load demand for each time interval over the scheduling period is given in Table 1. The best results obtained through various methos and from the MABC method are shown in Table 2. It clear from the table that the proposed method produces much better results compared to recently reported different methods for solving DED problem. The best total production cost obtained using proposed method is $\$ 40122.2954$ and the computation time taken by the algorithm is $43.718 \mathrm{~s}$. The optimum scheduling of generating units for 24 hours using proposed method is given in Table 3.

Table 1. Load Demand for 24 Hours (5-Unit System)

\begin{tabular}{cccccccc}
\hline $\begin{array}{c}\text { Time } \\
\text { (h) }\end{array}$ & $\begin{array}{c}\text { Load } \\
\text { (MW) }\end{array}$ & $\begin{array}{c}\text { Time } \\
\text { (h) }\end{array}$ & $\begin{array}{c}\text { Load } \\
\text { (MW) }\end{array}$ & $\begin{array}{c}\text { Time } \\
\text { (h) }\end{array}$ & $\begin{array}{c}\text { Load } \\
\text { (MW) }\end{array}$ & $\begin{array}{c}\text { Time } \\
\text { (h) }\end{array}$ & $\begin{array}{c}\text { Load } \\
\text { (MW) }\end{array}$ \\
\hline 1 & 410 & 7 & 626 & 13 & 704 & 19 & 654 \\
2 & 435 & 8 & 654 & 14 & 690 & 20 & 704 \\
3 & 475 & 9 & 690 & 15 & 654 & 21 & 680 \\
4 & 530 & 10 & 704 & 16 & 580 & 22 & 605 \\
5 & 558 & 11 & 720 & 17 & 558 & 23 & 527 \\
6 & 608 & 12 & 740 & 18 & 608 & 24 & 463 \\
\hline
\end{tabular}

Table 2. Comparison of Results for 5-Unit System

\begin{tabular}{lll}
\hline Method & Production cost (\$) & Computing time (s) \\
\hline SA [7] & 47356 & 351.98 \\
DE [8] & 43213 & 376 \\
PSO [9] & 50124 & 258.00 \\
ABC [12] & 44045.83 & NA \\
MABC & 40122.2954 & 43.718 \\
\hline
\end{tabular}

NA denotes that the value was not available in the literature.

Table 3. Best Scheduling of 5-Unit System Using MABC Method

\begin{tabular}{|c|c|c|c|c|c|c|c|}
\hline Hour & $\begin{array}{c}\text { P1 } \\
(\mathrm{MW})\end{array}$ & $\begin{array}{c}\text { P2 } \\
(\mathrm{MW})\end{array}$ & $\begin{array}{c}\mathrm{P} 3 \\
(\mathrm{MW})\end{array}$ & $\begin{array}{c}\mathrm{P} 4 \\
(\mathrm{MW})\end{array}$ & $\begin{array}{c}\text { P5 } \\
\text { (MW) }\end{array}$ & Cost $(\$)$ & $\begin{array}{l}\text { Ploss } \\
\text { (MW) }\end{array}$ \\
\hline 1 & 15.9000 & 74.6110 & 65.3926 & 113.9821 & 143.7123 & 1202.8966 & 3.5980 \\
\hline 2 & 16.4689 & 75.2536 & 68.7360 & 125.2026 & 153.3943 & 1260.0539 & 4.0554 \\
\hline 3 & 18.1862 & 80.6117 & 77.8790 & 140.3266 & 162.8244 & 1352.6344 & 4.8278 \\
\hline 4 & 20.4935 & 86.0723 & 96.6599 & 160.3596 & 172.3869 & 1482.0066 & 5.9722 \\
\hline 5 & 21.5864 & 89.1998 & 103.9743 & 166.6423 & 183.2109 & 1548.8321 & 6.6137 \\
\hline 6 & 22.7800 & 97.1001 & 109.2865 & 187.4793 & 199.2541 & 1669.9284 & 7.8999 \\
\hline 7 & 24.9083 & 96.9727 & 123.1182 & 193.9147 & 195.4027 & 1713.7105 & 8.3167 \\
\hline 8 & 25.4661 & 99.4240 & 132.6351 & 196.6955 & 208.8397 & 1782.7959 & 9.0605 \\
\hline 9 & 27.1946 & 104.6222 & 147.4868 & 210.9714 & 209.7943 & 1872.3901 & 10.0693 \\
\hline 10 & 27.3792 & 105.0382 & 147.1780 & 222.1217 & 212.7978 & 1907.5325 & 10.5149 \\
\hline 11 & 29.2308 & 107.9706 & 150.1629 & 227.9499 & 215.6908 & 1947.9061 & 11.0050 \\
\hline 12 & 29.7396 & 109.8457 & 156.8215 & 230.4698 & 224.7371 & 1998.6549 & 11.6137 \\
\hline 13 & 28.7616 & 107.6824 & 149.3106 & 218.7602 & 209.9832 & 1907.5458 & 10.4979 \\
\hline 14 & 28.1167 & 105.6265 & 144.0928 & 208.6829 & 213.5594 & 1872.3991 & 10.0783 \\
\hline 15 & 26.2046 & 100.9082 & 133.5592 & 201.4110 & 200.9790 & 1782.7041 & 9.0619 \\
\hline 16 & 22.5439 & 92.9996 & 107.7045 & 176.5454 & 187.3638 & 1601.7711 & 7.1572 \\
\hline 17 & 21.6900 & 89.5536 & 106.5160 & 169.8248 & 177.0206 & 1548.8295 & 6.6049 \\
\hline 18 & 24.3860 & 96.5779 & 112.6824 & 188.8729 & 193.3567 & 1669.7625 & 7.8759 \\
\hline 19 & 26.2384 & 101.0051 & 134.1256 & 196.7138 & 204.9696 & 1782.7391 & 9.0525 \\
\hline 20 & 28.5897 & 105.6929 & 145.2721 & 28.6371 & 216.3205 & 1907.5198 & 10.5123 \\
\hline 21 & 26.8848 & 102.5297 & 140.0851 & 206.3445 & 213.9508 & 1847.4105 & 9.7949 \\
\hline 22 & 24.1782 & 95.8857 & 117.3797 & 182.3840 & 192.9371 & 1662.3964 & 7.7647 \\
\hline 23 & 19.2625 & 86.7246 & 103.5288 & 151.9370 & 171.4194 & 1475.0242 & 5.8723 \\
\hline 24 & 17.6299 & 72.5581 & 81.2373 & 138.5930 & 157.5374 & 1324.8510 & 4.5557 \\
\hline
\end{tabular}

Case 2: 10-unit system

The second test system is a 10-unit test system. In this case, generator capacity limits, ramp rate constraints, valve-point effects and transmission losses are considered. The data for this system can be found 
from [13], [21]. The load demand for each time interval over the scheduling period is given in Table 4. The best solution obtained through the proposed method is compared to those reported in the recent literature are shown in Table 5. The best total production cost obtained using proposed method is $\$ 1022205.6846$ and the computation time taken by the algorithm is $45.61 \mathrm{~s}$. It clear from the table that the proposed method produces much better results compared to recently reported different methods for solving DED problem. The optimal dispatch of real power for the given scheduling horizon using MABC algorithm is given in Table 6.

Table 4. Load Demand for 24 Hours (10-Unit System)

\begin{tabular}{cccccccc}
\hline $\begin{array}{c}\text { Time } \\
(\mathrm{h})\end{array}$ & $\begin{array}{c}\text { Load } \\
(\mathrm{MW})\end{array}$ & $\begin{array}{c}\text { Time } \\
(\mathrm{h})\end{array}$ & $\begin{array}{c}\text { Load } \\
(\mathrm{MW})\end{array}$ & $\begin{array}{c}\text { Time } \\
(\mathrm{h})\end{array}$ & $\begin{array}{c}\text { Load } \\
(\mathrm{MW})\end{array}$ & $\begin{array}{c}\text { Time } \\
(\mathrm{h})\end{array}$ & $\begin{array}{c}\text { Load } \\
(\mathrm{MW})\end{array}$ \\
\hline 1 & 1036 & 7 & 1702 & 13 & 2072 & 19 & 1776 \\
2 & 1110 & 8 & 1776 & 14 & 1924 & 20 & 2072 \\
3 & 1258 & 9 & 1924 & 15 & 1776 & 21 & 1924 \\
4 & 1406 & 10 & 2072 & 16 & 1554 & 22 & 1628 \\
5 & 1480 & 11 & 2146 & 17 & 1480 & 23 & 1332 \\
6 & 1628 & 12 & 2220 & 18 & 1628 & 24 & 1184 \\
\hline
\end{tabular}

Table 5. Comparison of Results for 10-Unit System

\begin{tabular}{lll}
\hline Method & Production cost $(\$)$ & Computing Time (s) \\
\hline GA [12] & 1052251 & NA \\
PSO [12] & 1048410 & NA \\
ABC [12] & 1043381 & NA \\
ICA [13] & 1040758.424 & NA \\
MABC & 1022205.6846 & 45.61 \\
\hline NA denotes that the value was not available in the literature.
\end{tabular}

Table 6. Best Scheduling of 10-Unit System Using MABC Method

\begin{tabular}{|c|c|c|c|c|c|c|c|c|c|c|}
\hline Hour & $\begin{array}{c}\text { P1 } \\
\text { (MW) }\end{array}$ & $\begin{array}{c}\mathrm{P} 2 \\
(\mathrm{MW})\end{array}$ & $\begin{array}{c}\text { P3 } \\
\text { (MW) }\end{array}$ & $\begin{array}{c}\mathrm{P} 4 \\
(\mathrm{MW})\end{array}$ & $\begin{array}{c}\text { P5 } \\
\text { (MW) }\end{array}$ & $\begin{array}{c}\mathrm{P} 6 \\
(\mathrm{MW})\end{array}$ & $\begin{array}{c}\text { P7 } \\
\text { (MW) }\end{array}$ & $\begin{array}{c}\text { P8 } \\
\text { (MW) }\end{array}$ & $\begin{array}{c}\text { P9 } \\
\text { (MW) }\end{array}$ & $\begin{array}{c}\mathrm{P} 10 \\
\text { (MW) }\end{array}$ \\
\hline 1 & 152.8696 & 135.0000 & 215.5641 & 60.0000 & 73.0000 & 160.0000 & 130.0000 & 47.0000 & 20.0000 & 55.0000 \\
\hline 2 & 169.4802 & 135.0000 & 275.0999 & 60.0000 & 73.0000 & 160.0000 & 130.0000 & 47.0000 & 20.0000 & 55.0000 \\
\hline 3 & 250.1791 & 141.0615 & 340.0000 & 60.0000 & 73.0000 & 160.0000 & 130.0000 & 47.0000 & 20.0000 & 55.0000 \\
\hline 4 & 310.1379 & 194.5668 & 340.0000 & 60.0000 & 112.1634 & 160.0000 & 130.0000 & 47.0000 & 20.0000 & 55.0000 \\
\hline 5 & 338.1778 & 219.5432 & 340.0000 & 60.0000 & 136.0085 & 160.0000 & 130.0000 & 47.0000 & 20.0000 & 55.0000 \\
\hline 6 & 394.7858 & 270.1395 & 340.0000 & 60.0000 & 183.7220 & 160.0000 & 130.0000 & 47.0000 & 20.0000 & 55.0000 \\
\hline 7 & 423.1917 & 295.6766 & 340.0000 & 60.0000 & 207.8462 & 160.0000 & 130.0000 & 47.0000 & 20.0000 & 55.0000 \\
\hline 8 & 449.8081 & 315.7420 & 340.0000 & 60.0000 & 226.4674 & 160.0000 & 130.0000 & 59.0390 & 20.0000 & 55.0000 \\
\hline 9 & 458.5437 & 405.8813 & 340.0000 & 116.4564 & 229.9376 & 160.0000 & 130.0000 & 57.0359 & 20.0000 & 55.0000 \\
\hline 10 & 468.0060 & 407.8974 & 340.0000 & 205.4083 & 230.9734 & 160.0000 & 130.0000 & 93.9985 & 31.9882 & 55.0000 \\
\hline 11 & 466.5000 & 455.708 & 340.0000 & 188.3701 & 221.3598 & 160.0000 & 130.0000 & 154.6791 & 28.5092 & 55.0000 \\
\hline 12 & 469.9657 & 421.3228 & 340.0000 & 269.8678 & 232.3764 & 160.0000 & 130.0000 & 170.0000 & 24.6103 & 55.0000 \\
\hline 13 & 468.0312 & 452.3119 & 340.0000 & 139.4186 & 224.7564 & 160.0000 & 130.0000 & 134.8804 & 20.0000 & 55.0000 \\
\hline 14 & 469.6347 & 391.2385 & 340.0000 & 91.5604 & 241.0817 & 160.0000 & 130.0000 & 73.5287 & 20.0000 & 55.0000 \\
\hline 15 & 449.4984 & 314.2598 & 340.0000 & 60.0000 & 228.0280 & 160.0000 & 130.0000 & 59.2178 & 20.0000 & 55.0000 \\
\hline 16 & 366.4984 & 244.7241 & 340.0000 & 60.0000 & 159.7641 & 160.0000 & 130.0000 & 47.0000 & 20.0000 & 55.0000 \\
\hline 17 & 338.2203 & 219.5821 & 340.0000 & 60.0000 & 135.9280 & 160.0000 & 130.0000 & 47.0000 & 20.0000 & 55.0000 \\
\hline 18 & 394.8125 & 270.0284 & 340.0000 & 60.0000 & 183.8036 & 160.0000 & 130.0000 & 47.0000 & 20.0000 & 55.0000 \\
\hline 19 & 449.1781 & 315.7060 & 340.0000 & 60.0000 & 227.0256 & 160.0000 & 130.0000 & 59.1384 & 20.0000 & 55.0000 \\
\hline 20 & 467.6119 & 418.5122 & 340.0000 & 157.3762 & 235.5685 & 160.0000 & 130.0000 & 137.8902 & 20.0000 & 55.0000 \\
\hline 21 & 465.9263 & 411.1727 & 340.0000 & 71.9382 & 235.4961 & 160.0000 & 130.0000 & 83.3707 & 20.0000 & 55.0000 \\
\hline 22 & 394.8450 & 269.9871 & 340.0000 & 60.0000 & 183.8113 & 160.0000 & 130.0000 & 47.0000 & 20.0000 & 55.0000 \\
\hline 23 & 282.2374 & 169.7011 & 340.0000 & 60.0000 & 88.4561 & 160.0000 & 130.0000 & 47.0000 & 20.0000 & 55.0000 \\
\hline 24 & 207.8453 & 135.0000 & 312.5109 & 60.0000 & 73.0000 & 160.0000 & 130.0000 & 47.0000 & 20.0000 & 55.0000 \\
\hline
\end{tabular}

\section{CONCLUSION}

In this paper, a modified $\mathrm{ABC}$ algorithm is proposed to solve the non-convex dynamic economic dispatch problem. The proposed $\mathrm{MABC}$ algorithm employs a new mutation strategy inspired from the differential evolution (DE) to enhance the performance of the conventional ABC algorithm. The differential mutation is devised to improve the global searching capability and to enhance the capability of escaping from a local minimum. The effectiveness of the proposed method is illustrated by using a 5-unit and 10-unit test systems and compared with the results obtained from other method. It is evident from the comparison that the 
proposed technique provides better results than other methods in terms of minimum production cost and computation time.

\section{REFERENCES}

[1] X.S. Han, H.B. Gooi, and D.S. Kirschen, "Dynamic Economic Dispatch: feasible and optimal solutions", IEEE Transactions on Power Systems, vol. 16, no. 1, pp. 22-28, 2001.

[2] X. Xia, and A.M. Elaiw, "Optimal Dynamic Economic Dispatch of Generation: A review", Elect. Power Syst. Res., vol. 80, no. 8, pp. 975- 986, 2010.

[3] G.P. Granelli, P. Marannino, M. Montagna, and A. Silvestri, "Fast and Efficient Gradient Projection Algorithm for Dynamic Generation Dispatching”, IEE Proc. Gen.Trans. Distr., vol. 136, pp. 295-302, September 1989.

[4] K.S. Hindi and M.R. AbdGhani, "Dynamic Economic Dispatch for Large Scale Power Systems: A Lagrangian Relaxation Approach”, Elect. Power Syst. Res., vol. 43, pp. 51-56, 1991.

[5] C.B. Samuah, and N. Khunaizi, "Application of Linear Programming Re-Dispatch Technique to Dynamic Generation Allocation”, IEEE Transactions on Power Systems, vol. 5, pp. 20-26, 1990.

[6] F. Li, R. Morgan and D. Williams, "Hybrid Genetic Approaches to Ramping Rate Constrained Dynamic Economic Dispatch", Electric Power Systems Research, vol. 43, pp. 97-103, 1997.

[7] C.K. Panigrahi, P.K. Chattopadhyay, R.N. Chakrabarti and M. Basu, "Simulated Annealing Technique for Dynamic Economic Dispatch", Electric Power Components and Systems, vol. 34, pp. 577-86, 2006.

[8] R. Balamurugan, and S. Subramanian, "Differential Evolution-based Dynamic Economic Dispatch of Generating Units with Valve-Point Effects", Electric Power Components and Systems, vol. 36, pp. 828-43, 2008.

[9] G. Sreenivasan, C.H. Saibabu and S. Sivanagaraju,"Solution of Dynamic Economic Load Dispatch (DELD) Problem with Valve Point Loading Effects and Ramp Rate Limits using PSO”, International Journal of Electrical and Computer Engineering, vol. 1, no. 1, pp. 59-70, 2011.

[10] P. Attaviriyanupap, H. Kita, E. Tanaka, and J. Hasegawa,"A Hybrid EP and SQP for Dynamic Economic Dispatch with Nonsmooth Fuel Cost Function", IEEE Transactions on Power Systems, vol. 17, no. 2, pp. 411-416, May 2002.

[11] T. Aruldoss Albert Victoire, and A. Ebenezer Jayakumar, "Deterministically Guided PSO for Dynamic Dispatch Considering Valve-Point-Effect," Elect. Power Syst. Res., vol. 73, no. 3, pp. 313-322, 2005.

[12] S. Hemamalini and S. Simon, "Dynamic Economic Dispatch using Artificial Bee Colony Algorithm for Unit with Valve-Point-Effect," European Transactions on Electrical Power, vol. 21, pp. 70-81, 2011.

[13] BehnamMohammadi-ivatloo, Abbas Rabiee, AlirezaSoroudi, and Mehdi Ehsan, "Imperialist Competitive Algorithm for Solving Non-convex Dynamic Economic Power Dispatch,” Energy, vol. 44, pp. 228-240, 2012.

[14] D. Karaboga and B. Basturk, "On the Performance of Artificial Bee Colony (ABC) Algorithm", Applied Soft Computing, vol. 8, no. 1, pp. 687- 697, 2008.

[15] D. Karaboga and B. Akay, "Artificial Bee Colony (ABC), Harmony Search and Bees Algorithms on Numerical Optimization", Proceedings of IPROMS 2009 Conference, pp. 1-6, 2009.

[16] B. Akay and D. Karaboga, "A Modified Artificial Bee Colony Algorithm for Real-Parameter Optimization", Information Sciences, vol. 192, pp. 120-142, 2012.

[17] X.T. Li, X.W. Zhao, J.N. Wang and M.H. Yin, "Improved Artificial Bee Colony for Design of a Reconfigurable Antenna Array with Discrete Phase Shifters", Progress in Electromagnetics Research C, vol. 25, pp. 193-208, 2012.

[18] J.B. Park, K.S. Lee, J.R. Shin and K.Y. Lee, "A Particle Swarm Optimization for Economic Dispatch with Non Smooth Cost Functions", IEEE Transactions on Power Systems, vol. 20, no. 1, pp. 34-42, 2005.

[19] R. Storn and K. Price, "Differential Evolution a Simple and Efficient Heuristic for Global Optimization over Continuous Spaces", Journal of Global Optimization, vol. 11, no. 4, pp. 341-359, 1997.

[20] K. Price, R. Storn, and J.A. Lampinen, "Differential Evolution: A Practical Approach to Global Optimization", Springer, Berlin, Heidelberg, 2005.

[21] R. Balamurugan, and S. Subramanian, "An Improved Differential Evolution based Dynamic Economic Dispatch with Nonsmooth Fuel Cost Function”, Journal of Electrical Systems, vol. 3, no. 3, pp. 151-61, 2007.

\section{BIOGRAPHY OF AUTHOR}

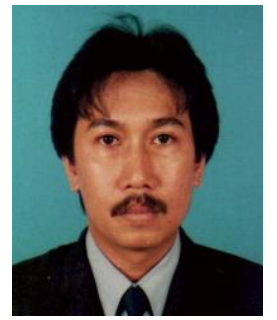

Hardiansyah was born on February 27, 1967 in Mempawah, Indonesia. He received the B.S. degree in Electrical Engineering from the University of Tanjungpura in 1992 and the M.S. degree in Electrical Engineering from Bandung Institute of Technology (ITB), Indonesia in 1996. Dr. Eng, degree from Nagaoka University of Technology in 2004. Since 1992, he has been with Department of Electrical Engineering, University of Tanjungpura, Pontianak, Indonesia. Currently, he is a senior lecturer in Electrical Engineering. His current research interests include power system operation and control, robust control, and soft computing techniques in power system. 